\title{
Correction to: Arsenic concentration, speciation, and risk assessment in sediments of the Xijiang River basin, China
}

\author{
Hai-bo Wang • Jia-ming Xu • Mario Alberto Gomez • \\ Zhong-liang Shi $\cdot$ Shi-feng Li $\cdot$ Shu-yan Zang
}

Published online: 19 December 2019

(C) Springer Nature Switzerland AG 2019

\section{Correction to: Environ Monit Assess (2019) 191:663 https://doi.org/10.1007/s10661-019-7883-4}

In the original paper, there was an error in the communication unit 1 . The communication unit was "Liaoning Engineering Research Center for Treatment and Recycling of Industrially Discharged Heavy Metals, Shenyang University of Chemical Technology, Shenyang 110142, People's Republic of China" rather than "Liaoning Engineering Research Center for Treatment and Recycling of Industrially Discharged Heavy Metals, Shenyang 110142, People's Republic of China”.
The corrected affiliation is shown below.

Publisher's note Springer Nature remains neutral with regard to jurisdictional claims in published maps and institutional affiliations.

The online version of the original article can be found at https://doi.org/10.1007/s10661-019-7883-4

H.-b. Wang · J.-m. Xu • M. A. Gomez · Z.-1. Shi $(\triangle) \cdot$

S.-f. Li $(\bowtie) \cdot$ S.-y. Zang

Liaoning Engineering Research Center for Treatment and

Recycling of Industrially Discharged Heavy Metals, Shenyang

University of Chemical Technology, Shenyang 110142, People's

Republic of China

e-mail: shzh12000@163.com

e-mail: li.shi.feng@163.com

H.-b. Wang

College of Environmental and Safety Engineering, Shenyang University of Chemical Technology, Shenyang 110142, People's

Republic of China 